\title{
CRIME, SUJEITO E SUJEIÇÃO CRIMINAL': ASPECTOS DE UMA CONTRIBUIÇÃO ANALÍTICA SOBRE A CATEGORIA "BANDIDO"
}

Michel Misse

Muitas contribuições recentes à teoria do sujeito têm argumentado que a experiência de tornar-se sujeito está vinculada fundamentalmente à experiência da subjugação. Nesse sentido, o sujeito seria o pressuposto da agência, já que não se pode explicá-la sem a intervenção ativa que contrapõe a estrutura. Se tomarmos estrutura como poder (mesmo no sentido amorfo weberiano), então a experiência da sujeição (no sentido de subjugação, subordinação, assujetissement) seria também o processo através do qual a subjetivação - a emergência do sujeito - se ativa como contraposto da estrutura, como ação negadora. O sujeito, nesse sentido, é o efeito de ser posto pela estrutura (poder) e de emergir como seu ser contraposto e reflexivo (potência). É assim que autores como Foucault (1977, 1984, 1988, 2006), Althusser (1972), Butler (1997, 2005) e, mais recentemente, Das (1989, 2005) e Das et al. (1997), tentam responder ao persistente paradoxo de se pensar a ação reflexiva e a interação

\footnotetext{
${ }^{1}$ Sobre o conceito de "sujeição criminal", ver Misse (1999). Aproveito, neste artigo, trechos de minha argumentação primeiramente apresentada naquele estudo. A este respeito, ver também Misse (2006).
} 
sem perder de vista suas determinações, particularmente do ângulo de quem se encontra subalterno.

Entretanto, essas contribuições tendem a pensar o sujeito social que emerge da experiência de subordinação como "sujeito revolucionário" que põe novos valores (marxismo, feminismo, movimento gay, ecologia etc.); raramente o tomam pela sua ação egoísta, voltada para si ou para seu grupo, cínica ou cética quanto à necessidade do Outro que não seja sob a forma também da subordinação ou de sua subjugação. Dito de outro modo: raramente o sujeito que emerge da experiência da subordinação é pensado como sujeito que subordina ou que subjuga, que produz outros assujeitamentos e, portanto, também outros sujeitos. Um dos argumentos para não pensá-lo como sujeito é exatamente o fato de que ele não põe valores, não é "democrático" (Wiewiorka, 2008). Entretanto, se o negamos como sujeito, caímos em novos paradoxos, entre os quais o de repor o conflito entre ação e 16 estrutura, para os quais teríamos dois pesos e duas medidas. Afinal, o que queremos dizer quando afirmamos que o "ator pensa", que o "ator sofre", que o "ator ama"? Pensar, sofrer e amar não são categorias assimiláveis analiticamente nem à estrutura, nem aos papéis, nem ao ator e nem à agência.

A sociologia convencional tem preferido esquivar-se desses problemas refugando a discussão sobre o processo de subjetivação à psicologia, à psicanálise, à filosofia e aos chamados cultural studies, e defendendo no plano micro a autonomia constitutiva da interação social, através dos conceitos clássicos de self, identidade social, ator social, papéis e status sociais. Para ligar esse plano de categorias interacionistas ao plano da estrutura, das instituições, das práticas e da ação coletiva recorre por vezes à noção de agência. Se tomarmos importantes contribuições que lidam com temas como o nosso, por exemplo, os trabalhos de Erving Goffman e Howard S. Becker, observaremos o quanto noções como "estigma" e "rótulo" tensionam com essa tradição mas evi- 
tam confrontar diretamente a categoria implícita do sujeito que sofre e manipula o estigma ou que rotula ou é rotulado, preferindo permanecer no ocultamento tático do sujeito sob o self social. De alguma maneira, o sujeito é posto "fora" do self, como seu "fundo" ou sua "essência", para melhor se livrar dele. O sujeito do self, como já se disse inúmeras vezes, não pertenceria à sociologia, assim como o descascar das camadas da cebola não nos conduz a qualquer "profundidade"; quando a buscamos, não encontramos nada além da própria cebola descascada. No entanto, o paradoxo persiste, pois há um agir que se define por sua autonomia frente à estrutura, frente à função e contra o "já dado", que põe e resgata o sujeito em algum lugar que está no self mas que, ao mesmo tempo, o nega e o ultrapassa no desejo, nas emoções, na produção do sentido e na ação reflexiva propriamente dita. O sujeito não está em qualquer profundidade do self, é apenas uma outra forma de abordá-lo.

As minhas pesquisas têm me conduzido à constatação de que há vários tipos de subjetivação que processam um sujeito não revolucionário, não democrático, não igualitário e não voltado ao bem comum. O mais conhecido desses tipos é o sujeito que, no Brasil, é rotulado como "bandido", o sujeito criminal que é produzido pela interpelação da polícia, da moralidade pública e das leis penais. Não é qualquer sujeito incriminado, mas um sujeito por assim dizer "especial", aquele cuja morte ou desaparecimento podem ser amplamente desejados. Ele é agente de práticas criminais para as quais são atribuídos os sentimentos morais mais repulsivos, o sujeito ao qual se reserva a reação moral mais forte e, por conseguinte, a punição mais dura: seja o desejo de sua definitiva incapacitação pela morte física, seja o ideal de sua reconversão à moral e à sociedade que o acusa. O eufemismo de "ressocialização" ou de "reinserção social" acusa, aqui, por denotá-la, a "autonomia" desse "sujeito", e paradoxalmente a sua "não sujeição" às regras da sociedade. 
A minha questão envolve a constatação de uma complexa afinidade entre certas práticas criminais - as que provocam abrangente sentimento de insegurança na vida cotidiana das cidades - e certos "tipos sociais" de agentes demarcados (e acusados) socialmente pela pobreza, pela cor e pelo estilo de vida. Seus crimes os diferenciam de todos os outros autores de crime, não são apenas criminosos; são "marginais", "violentos", "bandidos".

Tenho procurado entender esse complexo processo social, que teve no Rio de Janeiro o seu primeiro e mais conhecido desdobramento no Brasil, como o de uma "acumulação social da violência” (Misse, 1999; 2006; 2008a). É como se alguns fatores sociais se alimentassem reciprocamente em algo como uma causação circular acumulativa, gerando, de um lado, acumulação de desvantagens para um segmento da população e, de outro, estratégias aquisitivas partilhadas tanto por agentes criminais quanto por agen18 tes encarregados de reprimi-los, de um modo que ganhou diferentes graus de legitimação em importantes camadas da sociedade mais abrangente. Além da associação entre acumulação de desvantagens e incriminação preventiva de certos "tipos sociais", desenvolveu-se um persistente processo de "sujeição criminal" de uma parcela de agentes de práticas criminais. Tal dinâmica terminou por constituir algo como uma "cultura" associada a esses sujeitos.

Para sublinhar uma importante dimensão do que estou chamando de sujeição criminal é preciso compreender que, no Brasil, pelo menos a partir de meados dos anos 1950, sempre houve certa justificação, eu não diria consensual, mas habitual, para a eliminação física de criminosos comuns, mesmo quando sua "periculosidade" não poderia servir para justificá-la. Há inúmeras descrições, por exemplo, de vinganças contra pequenos ladrões submetidos a torturas em rituais públicos de degradação e crueldade. Trata-se do deslizamento de sentido da punição pelo cri- 
me cometido para a punição do sujeito "porque" criminoso "contumaz": para o que seria seu incorrigível "mau-caráter", sua subjetividade essencialmente criminosa, má; para sua irrecuperabilidade potencial. Tudo isso não é algo que se deva deixar de lado quando se tem em mente os sucessivos esquadrões da morte, a difusão dos grupos de extermínio e a confusão moral de praticar crimes para "justificadamente" punir crimes. Esquadrões e grupos de extermínio não poderiam existir durante tanto tempo se não existisse algum tipo de ambientação social em busca de sua legitimação. Do mesmo modo, o volume de suspeitos que são mortos pela polícia em vários estados brasileiros, especialmente no Rio de Janeiro, aponta para ao menos duas questões: o quanto estão sendo simplesmente executados e, se não for o caso, por que preferem o risco da morte a se entregar à polícia, como em outros lugares. Se há mesmo um confronto legal, como explicar que a polícia fluminense tenha matado mais de 10 mil suspeitos de crime no mesmo período em que perdeu, em serviço, menos de quatrocentos de seus homens?

Esse processo de sujeição criminal ganhou uma nova dimensão quando os mercados de trabalho ilegais convencionais, tradicionais, principalmente o mercado de trabalho do jogo do bicho, que era local e depois se torna nacional, vão sendo tragados, aos poucos, por um novo mercado de trabalho, uma empresa altamente lucrativa, relativamente desorganizada e amplamente disseminada, como é o varejo de drogas ilícitas, especialmente da cocaína. Em comparação com os mercados de trabalho ilegais convencionais, como a prostituição popular, o jogo, o pequeno contrabando, as vigarices, a compra e venda de objetos roubados e mesmo o jogo do bicho, o varejo da cocaína mostrou-se extremamente atraente para os padrões de renda das populações que atingiu. Despertava também, curiosamente, menor reação moral local, por oposição aos crimes convencionais. 
Redes de quadrilhas foram se constituindo e abarcando os diferentes aglomerados urbanos de baixa renda - favelas, conjuntos habitacionais, "lotes" da periferia - de um modo muito característico: vários pontos de venda fixos, guarnecidos por "soldados", a partir dos quais pequenos vendedores, os "vapores", oferecem a mercadoria a usuários locais ou que vêm de outras partes da cidade. Naturalmente, toda a área desses "pontos de venda" terminava confundindo-se com o aglomerado urbano do qual fazia parte, constituindo-se assim num "território" do tráfico a ser defendido, a ferro e fogo, de outras redes de quadrilhas e das incursões da polícia.

Uma parte importante da explicação dessa associação do varejo do tráfico com a violência deve-se ao surgimento de quadrilhas que controlam territórios em áreas urbanas de baixa renda, o que leva a intermitentes conflitos com outras quadrilhas pelo controle desses territórios e de seus pontos 20 de venda. Do mesmo modo, o baixo poder aquisitivo dos que operam nesses territórios torna-os vulneráveis a um sistema de consignação de vendas em que a dívida é paga com a morte. $\mathrm{O}$ tráfico de drogas, que atende às elites e às classes médias em praticamente todos os países do mundo, inclusive no Brasil, não se associa da mesma maneira à violência, principalmente porque é operado por indivíduos e não por quadrilhas e não é baseado em controle de territórios, mas em relação direta com o consumidor, através da entrega em domicílio ou em lugares combinados. Não há, portanto, uma relação necessária entre drogas ilícitas e montante da violência, a não ser quando o tráfico se territorializa e opera com jovens pobres, submetidos ao sistema da consignação de vendas e à relação de subordinação ao chefe da quadrilha (Zaluar, 2004; Misse, 2006; Grillo, 2008).

Nesse sentido, a sujeição criminal também se "territorializa", ganha contornos espaciais e amplifica-se nos sujeitos locais e mesmo nas crianças e adolescentes cuja sujei- 
ção é esperada ${ }^{2}$. Como tal, não pode ser compreendida exclusivamente apenas no plano da interação contextual e do desempenho de papéis sociais, pois se mostra ancorada num plano macro de acumulação social da violência em tipos sociais constituídos e representados por sujeitos criminais produzidos em contextos sócio-históricos determinados. Aqui a sujeição criminal poderia ser compreendida, ao mesmo tempo, como um processo de subjetivação e o resultado desse processo para o ponto de vista da sociedade mais abrangente que o representa como um mundo à parte. Por exemplo, "o mundo do crime" (Ramalho, 1983), que representa as pessoas que "fazem parte" desse mundo (como "malandros", "marginais", "traficantes", "bandidos") como sujeitos criminosos. Também por isso podemos considerar que a sujeição criminal é um processo de criminação de sujeitos, e não de cursos de ação. Trata-se de um sujeito que "carrega" o crime em sua própria alma; não é alguém que comete crimes, mas que sempre cometerá crimes, um bandido, um sujeito perigoso, um sujeito irrecuperável ${ }^{3}$, alguém que se pode desejar naturalmente que morra, que pode ser morto, que seja matável. No limite da sujeição criminal, o sujeito criminoso é aquele que pode ser morto ${ }^{4}$.

Originalmente, a sujeição criminal é apenas distintiva. Nesse sentido, ela sempre começa no plano da interação social contextual, mas já sob a referência estrutural do

\footnotetext{
${ }^{2}$ A Polícia do Rio de Janeiro matou nos últimos cinco anos (2004-2008), em suposto confronto legal, 5.600 civis suspeitos de crimes, dos quais 1.836 crianças e adolescentes. Ver o Diário Oficial do Estado do Rio de Janeiro (http://www.isp.rj.gov. br/Conteudo.asp?ident=150), para os dados sobre autos de resistência. Sobre a sujeição criminal de crianças e adolescentes, ver Misse (2007) e Néri (2009).

3 A ideia de "recuperabilidade" pode ser um bom divisor analítico entre sujeito simplesmente incriminado e sujeito criminal. De qualquer modo, aponta para "causas" a serem removidas no sujeito e, portanto, para a subjetividade na representação do que seja um criminoso. Sobre as mudanças nas representações sociais do que seja um criminoso, ver Melossi (2000).

${ }^{4}$ A conexão com as questões tratadas por Agambem (2007) é inevitável, mas ela não será analisada aqui.
} 
“criminal”. O referente está dado não apenas nos códigos penais, mas na própria linguagem que - na interação - será empregada para distinguir a ruptura da normalidade ou a sua expectativa em um sujeito. Se partirmos do pressuposto durkheimiano de que o crime não "existe" nem no evento nem em seu autor, mas na reação ao evento e ao autor, poderemos compreender melhor como se dá o processo como um todo. A acusação social que constrói o criminoso (e que coincide com o início do processo de incriminação) é sempre resultante de uma interpretação contextualizada, entre agentes, de cursos de ação cujo significado "normal" ou "desviante" se produz nesse mesmo processo e não antes dele. Evidentemente, há uma pauta classificatória dos crimes (o Código Penal, por exemplo) que é anterior e exterior ao evento e que é tomada como referência; mas essa pauta não existe senão no processo social que a aplica, que a interpreta, que a contextualiza ou que a despreza. E há 22 também a sensibilidade jurídica local, que nem sempre coincide ou concorda com os códigos peritos. O crime é definido primeiramente no plano das moralidades que se tornaram hegemônicas e cuja vitória será inscrita posteriormente nos códigos jurídicos.

Embora seja reconhecido que a definição de uma ação como desviante (divergente, problemática, desnormalizada ou que nome se lhe queira dar) depende de um julgamento baseado numa certa ideia de normalidade, e que as ideias sobre normalidade são lábeis e produzidas contextualmente entre os agentes envolvidos, são poucos os que reconhecem que nesse caso uma pauta relativamente fixa de significados de normalidade é apenas culturalmente referencial, e as definições de cada situação um processo social que ganha relativa autonomia em relação a essa pauta. Nesse caso, incluir um agente em algum item de uma pauta legal reconhecida, como por exemplo o Código Penal, que é o que estamos chamando aqui de "incriminação", não é uma ação simples e direta de 
encaixamento, mas um complexo processo de interpretação baseado também em poderes de definição da situação. Todo esse processo é reconhecidamente uma construção social (Misse, 2008b). Vários autores trataram dele, no plano da teoria dos papéis sociais e de sua internalização pelo ator, atribuindo-lhe várias dimensões que se superpõem no conceito de "identidade social". É o caso pioneiro de Frank Tannenbaum (1938), quando afirma que "the person becomes the thing he is described as being". Edwin Lemert (1951; 1967) elabora esse processo chamando-o de "desvio secundário”, ao se referir ao indivíduo cuja autoconcepção de si e de suas ações se conforma substancialmente com a imagem desviante que os outros têm dele. É também o caso de Howard S. Becker (1963), John Kitsuse (1962) e Kai Erikson (1962) ao popularizarem como "rótulo" (label) esse tipo de status negativo atribuído ao desviante; e também de Erving Goffman (1962) ao denominar de "estigma" suas resultantes para a identidade social deteriorada, cuja manipulação pelo self ele estudou brilhantemente.

Na sujeição criminal encontramos esses mesmos processos, mas potencializados por um ambiente de profunda desigualdade social, forte privação relativa de recursos de resistência (ou ocultação social) à estigmatização e pela dominação (mais que apenas pelo predomínio) da identidade degradada sobre todos os demais papéis sociais do indivíduo. O rótulo "bandido" é de tal modo reificado no indivíduo que restam poucos espaços para negociar, manipular ou abandonar a identidade pública estigmatizada. Assim, o conceito de sujeição criminal engloba processos de rotulação, estigmatização e tipificação numa única identidade social, especificamente ligada ao processo de incriminação e não como um caso particular de desvio. Entre esse self socialmente degradado e subjugado pelo horizonte de risco de uma morte iminente, sem sentença e sem qualquer glória, e a emergência de um sujeito criminal inteiramente egoísta e indiferente ao 
destino dos outros, reificado em seu próprio atributo social, estende-se o continuum de dimensões do conceito.

A sujeição criminal não é apenas um rótulo arbitrário, ou o resultado de uma luta por significações morais disputáveis, mas um processo social que condensa determinadas práticas com seus agentes sob uma classificação social relativamente estável, recorrente e, enquanto tal, legítima. Há estruturação na produção social da sujeição criminal, mas cada evento só é capturado nessa estruturação se "fizer sentido" para muitos indivíduos, inclusive para o próprio acusado.

O conceito de "sujeição criminal” é proposto com a finalidade de determinar três dimensões incorporadas na representação social do "bandido" e de seus tipos sociais. A primeira dimensão é a que seleciona um agente a partir de sua trajetória criminável, diferenciando-o dos demais agentes sociais, através de expectativas de que haverá, em algum momento, demanda de sua incriminação. A segunda dimen24 são é a que espera que esse agente tenha uma "experiência social" específica, obtida em suas relações com outros bandidos e/ou com a experiência penitenciária. A terceira dimensão diz respeito à sua subjetividade e a uma dupla expectativa a respeito de sua autoidentidade: a crença de que o agente não poderá justificar sensatamente seu curso de ação ou, ao contrário, a crença em uma justificação que se espera que esse agente dê (ou que possa ser dada legitimamente a ele) para explicar por que segue reiteradamente nesse curso de ação criminável. Práticas criminais são todas as práticas crimináveis, isto é, que têm chance objetiva, numa dada sociedade e dada uma determinada "definição da situação", de serem criminadas e cujo agente sabe ter chance objetiva de ser submetido a um processo de incriminação.

É importante frisar que a sujeição criminal é o resultado, numa categoria social de indivíduos, de um processo social de constituição de subjetividades, identidades e subculturas do qual participam como fatores: 1) designações sociais que 
produzem uma específica "exclusão criminal" (através de acusações e incriminações) de agentes que caiam na classificação social do que seja delito (crime ou contravenção); 2) atribuições ao agente (baseada na crença de que sua trajetória confirma, nesse caso, regras sociais de experiência) de uma tendência a praticar crimes, isto é, de seguir um curso de ação incriminável, geralmente com a expectativa de que esse curso de ação venha a ter (ou já tenha) regularidade; 3) autorrepresentações, no agente, ou representações nos seus familiares, ou mesmo nos seus grupos de referência ou na comunidade em que vive, que ora demandam ou tentam "justificar" ou "explicar" suas práticas e escolhas individuais, ora as atribuem à sua singularidade ou concluem pela impossibilidade dessa justificação. A inexistência de quaisquer dessas dimensões exclui um agente da situação de sujeição criminal, mas não necessariamente da incriminação. Indivíduos que são eventualmente incriminados podem não incorporar (ou não serem socialmente incorporados) na sujeição criminal ${ }^{5}$. As práticas criminais não produzem sempre sujeição criminal.

Com esse conceito, pretendo estender uma ponte entre as abordagens interacionistas e pós-estruturalistas, de modo a contribuir para a compreensão desses processos sociais numa sociedade profundamente desigual, como é o caso do Brasil. Nesse sentido, representações de "periculosidade", de "irrecuperabilidade", de "crueldade" participam de processos de subjetivação que conduzem, no limite, à justificação do extermínio do sujeito criminal. Trata-se de um processo de inscrição do crime na subjetividade do agente, como numa possessão, e não apenas no seu comportamento criminável, tornando muitas vezes sua tentativa de "sair do mundo do crime" tão inverossímil para os outros a pon-

\footnotetext{
${ }^{5}$ Ver Magalhães (2006), sobre as narrativas de presos que explicitam contextos de sujeição criminal.
} 
to de exigir praticamente um processo de conversão (despossessão) de tipo religioso.

Para que haja sujeição criminal, é preciso que certos tipos de curso de ação, representados não apenas como desviantes, divergentes, problemáticos ou ilegais, mas denunciados principalmente como criminais, inclusive pelo agente, se reiterem na expectativa social a propósito desse agente; que esses tipos de curso de ação condensem significações de ruptura com representações de normas sociais de validez abrangente e, principalmente, rompam ou ameacem romper com o núcleo emocional dos agentes sociais, um núcleo forte sobre o qual se concentram as representações sociais da normalidade, do crime e da violência. Em oposição ao "não fiz por mal" do negligente e do "fui levado a isso" do neutralizador, ele pode chegar, no limite, a assumir publicamente sua identidade como "mau" ou se tornar inteiramente indiferente ao status negativo que continuam a lhe atribuir. Impor-se 26 pelo medo é uma das formas mais elementares e universais de operar o poder em condições de desconfiança recíproca. Nessa identificação-limite, e ainda aí, ele não desconhece a classificação social do que sejam boas ou más ações na esfera mais abrangente dos valores. Constituído como sujeito pleno no registro do atributo e no registro de suas próprias identificações e de sua vivência, no registro da moral e do direito, a ele se indaga: por que esse caminho? Agrupei suas variadas respostas em três tipos-ideais de autojustificação: o acaso ou o destino; a escolha racional; e a "vontade de..." (Misse, 1999). Diferentemente também da sujeição criminal que busca neutralização (íntima ou pública), embora ele geralmente veja razões para autocontrolar ou modificar seu destino, suas escolhas e sua própria vontade, pensa que poderá fazer isso "mais à frente", "algum dia talvez", "quando chegar a hora". Ele assume, de certa maneira, um livre-arbítrio que não nega a necessidade das normas e valores sociais, mas que o coloca, por assim dizer, "por algum tempo" acima deles. 
Nesse sentido, o "perigo" que tal agente passa a representar reforça a crença de que ele possua uma subjetividade peculiar, algo como um "carisma de valor negativo", mas que denota uma diferença que pode ser interpretada por ele como de "superioridade moral". Trazê-lo de volta à norma e à sociabilidade convencional representaria, portanto, um processo da magnitude de uma "conversão" ou "reconversão", e não é raro que esse processo se realize estritamente sob a forma de uma "conversão religiosa" .

A maior ou menor coincidência ou tensão entre a atribuição social e a autoidentificação do agente a um tipo ou a uma combinação de tipos sociais de sujeição criminal pode indicar diferentes dimensões tácitas de um jogo que envolve diretamente os agentes postos na posição acusatória, que formam para ele um out-group, os agentes postos na posição de parceiros ou iguais, ainda que de grupos rivais, que formam um in-group abrangente, e os agentes cuja posição combina ou oscila entre os dois grupos (mediadores, tanto em sentido positivo quanto negativo na diversa apreciação dos grupos de agentes). A "entrada no mundo do crime" é muito variada e muitas vezes ocasional. Para os objetivos deste trabalho, o que mais importa não é a entrada, nem mesmo a "adesão" ou a "opção" pelo crime, mas, na sua reiteração, tornar-se passível de incorporação numa identidade social negativa e sua consequente acomodação a um tipo social ${ }^{7}$.

\footnotetext{
${ }^{6}$ Ver o desenvolvimento dessa conexão em Teixeira (2009).

7 A "entrada no mundo do crime" (e, portanto, a incorporação da sujeição criminal) segue, muitas vezes, um padrão análogo (e culturalmente oposto) ao seguido pelo adolescente Zuni, estudado em célebre ensaio de Lévi-Strauss. O adolescente, acusado de feitiçaria, "tornou-se" feiticeiro à medida que procurava tacitamente explicar-se, perante os juizes, da acusação. "O acusado, preservado como testemunha, traz ao grupo uma satisfação de verdade, infinitamente mais densa e mais rica do que a satisfação de justiça que teria proporcionado a sua execução" (LéviStrauss, 1985, p. 201). O padrão é análogo e oposto porque, em nosso caso, o agente acusado submete-se à sujeição, "torna-se" bandido, muitas vezes por não conseguir escapar dessa identidade, testemunhando-a, recusando-a e atestando assim "a realidade do sistema que a tornou possível" (p. 200).
} 
Não há sujeição criminal sem incriminação, mas pode haver incriminação sem sujeição criminal. O que distingue radicalmente a incriminação de um indivíduo de sua sujeição criminal é representado socialmente, grosso modo, pela distinção entre "bandidos" e não bandidos. O significado de "bandido", embora remeta a "integrante de um bando", ganhou autonomia individualizante, passou a ser aplicada ao agente cuja sujeição criminal já está em curso ou que se considera consolidada. Na representação jurídica, a "reincidência" poderia aparecer como um indicador dessa distinção, e geralmente o é, mas não é suficiente. Pode haver reincidência criminal e não haver sujeição criminal, como pode haver sujeição criminal sem reincidência judicialmente registrada. De um modo geral, a diferença é construída pela ênfase maior que se dá ao sujeito, no caso da sujeição criminal, com a expectativa social de que o agente é, de algum modo, subjetivamente ligado à trans28 gressão; e pela ênfase maior na transgressão que no sujeito, no caso da mera incriminação, com a expectativa social de que aquela transgressão não é subjetivamente ligada ao agente (ao seu caráter, às suas origens e ao seu meio social, à sua biografia etc.).

De qualquer modo, quando o agente "sabe" que, ao empreender determinado curso de ação, ele poderá "cair" dentro de uma classificação social incriminadora, que ele conhece e com a qual até pode partilhar, logo uma autoavaliação se impõe: a que indica o quanto ele está (ou não) ligado subjetivamente a esse tipo de curso de ação e de que modo ele a interpreta. A maior ou menor capacidade e interesse do agente em fazer essa ligação e interpretá-la é a dimensão principal da sujeição criminal no âmbito do processo de subjetivação, e as tensões entre a imputação à subjetividade feita pelo acusador e pelo acusado (seja internamente ao agente, seja externamente entre agentes) permitem construir indicadores fecundos da variedade de situações em que os pode- 
res de definição da sujeição criminal são operados, seja para neutralizá-la, assimilá-la, incorporá-la ou agravá-la.

Além disso, diferentes representações sociais da diferença social entre o ilícito, o ilegal e o criminal permeiam a estratificação bandido/não bandido. Como toda sujeição criminal tende a produzir uma condensação com determinados tipos sociais e estes, por sua vez, podem conferir à sujeição criminal algumas de suas características, pode desenvolver-se uma específica "subcultura da sujeição criminal" que incorpora traços afins a outras subculturas. $\mathrm{O}$ fato que, de um modo geral, a representação social possa distinguir "crime" de "mundo do crime" e a lei distinguir, por exemplo, "contravenção" de "crime", exige que também a diferença entre incriminação e sujeição criminal se apoie na maior ou menor socialização do agente criminal numa subcultura representada como, no mínimo, desnormalizada e como, no máximo, criminal.

Não basta, portanto, à sujeição criminal, que ela ligue a subjetividade do agente à expectativa de reiteração da transgressão; é necessário também que essa ligação se dê em determinadas condições sociais, que definirão algo como uma estratificação social dos agentes passíveis de sujeição criminal. Pode-se, então, propor a hipótese de uma seleção social da sujeição criminal, que o processo de incriminação reproduz ampliadamente. Essa seleção tendencialmente acompanha as linhas da estratificação social mais abrangente. Do mesmo modo, as linhas de reiteração das práticas criminais dependem também de recursos de poder que, geralmente, acompanham a estratificação social, por dependerem de diferentes "poderes sociais de disposição" de bens materiais ou simbólicos. Certos tipos de criminação são condensados em certos tipos de agentes tanto por seleção social atributiva (ascribed) quanto por sua aquisição motivada (acquired). Mas não basta absorvê-la numa teoria dos papéis sociais: é preciso atentar para a profunda dimensão ideológica envolvida 
na constituição desse tipo de sujeito, que parece envolver um tipo-limite da própria noção de sociabilidade.

Quando vivida de forma extrema, a experiência da sujeição criminal, ao constituir um tipo de sujeito-limite ou um sujeito-em-ruptura com a ordem legítima dominante, aprofunda sua individuação e sua desafiliação numa direção que o torna passível de vivenciar, muitas vezes de forma radical, a incomunicabilidade dessa experiência social. De um modo análogo (e apenas análogo) à experiência do místico e do esquizofrênico, sua participação no registro da intersubjetividade parece-lhe, de algum modo, desnecessária, superficial ou mesmo impossível. Talvez por isso, várias das conversões que reintegram esse indivíduo à ordem social legítima, o reintegram também como um indivíduo especial, cuja vivência incomum é representada como passível de ter-lhe permitido acessar registros ontológicos incomuns. O carisma negativo se metamorfoseia em carisma positivo. 30 Não basta que haja conversão, é necessário dar-lhe o testemunho público. Não são poucos os casos em que o ex-bandido se transforme no seu tipo oposto, em pastor, sacerdote ou mesmo em "santo".

Quando a experiência da sujeição criminal não é tão radical assim, ou é atenuada por uma subcultura que lhe confere intersubjetividade suficiente para arrefecer essa individuação extrema, o indivíduo, que geralmente também não se desafiliou tão completamente dos vínculos que o integram à ordem legítima, poderá abandonar a sujeição criminal utilizando-se de recursos sociais mais variados e menos extremados. Ainda assim, sua experiência anterior lhe servirá para diferenciar-se do homem comum. Em muitos casos, por falta de recursos de reintegração ao mercado de trabalho, ele migrará para as

\footnotetext{
${ }^{8}$ Sartre representou a radicalidade dessas opções limítrofes em sua peça O Diabo $e$ o bom Deus, em que o personagem principal, Goetz, experimenta alternativamente a posição do "mal absoluto" e do "bem absoluto", antes de reconhecer sua relatividade para si próprio e para os outros.
} 
franjas da sujeição criminal, explorando as possibilidades de navegação entre o que aprendeu com a experiência anterior e o que poderá fazer agora, no interior e ao mesmo nas fronteiras da ordem legítima dominante.

Embora a sujeição criminal "retire" o indivíduo do seu contexto social comum para transferi-lo a um lugar socialmente separado (o "submundo", a "boca", o "ponto", o "antro" e, enfim, a "prisão"), esse "retiro", essa "exclusão criminal” nunca são completos. Ao contrário, apenas demarcam uma posição nas relações sociais, que continuam a se desenvolver sob a inflexão (ou não, pois depende de sua visibilidade social) da nova posição. Em alguns casos, mais extremos, a desafiliação poderá ser muito grande, mas raramente o contato social direto com vários tipos de indivíduos "não demarcados" deixará de existir. O desenvolvimento de subculturas que vinculam indivíduos que ocupam posições demarcadas pela sujeição criminal com os demais pode ser interpretado como uma "ampliação" ou uma "generalização" da sujeição criminal, primeiramente para o grupo que vivencia a sujeição e posteriormente para indivíduos e grupos que circulam em seu entorno ou que mantêm relações relativamente regulares com os que se encontram socialmente (ou são representados como) sob "exclusão criminal”, mas que não são "bandidos". Por razões de confidência e de reconhecimento recíproco, mas também por um processo identitário, desenvolvem-se códigos e linguagens próprios, cuja generalização aos grupos de entorno e até mesmo a segmentos da sociedade mais abrangente indica já o grau de sua sedimentação social, de sua antiguidade, de sua continuidade, de sua influência, bem como de suas metamorfoses e rupturas, ao se produzirem novos significados apoiados em significantes antigos ou ao se condensarem vários significados, algumas vezes ambíguos, num mesmo significante. Esses códigos e linguagens também são demarcados socialmente como "pertencentes" ou "originários" do submundo do 
crime e da contravenção e, quando utilizados em contextos sociais inadequados, podem estigmatizar quem os veicula.

A normalização dos modelos de conduta construiu-se também pela produção do autocontrole na utilização desses códigos e linguagens ou mesmo na sua negação durante o processo de socialização, através de fortes recriminações ao seu uso por crianças e adolescentes. Linguagens chulas, “populares", expressões de gíria, palavrões, gestos, determinados movimentos corporais, exteriorizações de paixões como a cólera, a inveja, o ciúme, o despeito etc., através dessas expressões e desses gestos codificados como "baixos", "sujos", mantêm, no entanto, uma abrangência social maior que a de seus "lugares" de origem ou de utilização mais frequente $^{9}$. Essa ampliação ou generalização dos códigos e linguagens do submundo para outras áreas da sociedade abrangente, se, por um lado, tende a ser parcial, seletiva e quase sempre contextualizada (entre homens e rapazes, 32 entre amigos ou em família), por outro, tem migrado mais rapidamente e com maior abrangência e frequência de uso, nas últimas décadas, para mais longe do entorno social da sujeição criminal, alcançando mesmo inúmeros segmentos da sociedade que anteriormente se fechavam mais a seu emprego. Signos antes contidos às representações que os próprios agentes faziam de suas práticas "desviantes", "diver-

\footnotetext{
${ }^{9}$ Dicionários das linguagens de gírias e palavrões são muito antigos. Localizei, por exemplo, um Dicionário dos malfeitores, editado em Lisboa em 1908. Em 1968, Carlos Lacerda, ex-governador do Rio, prefaciou um Dicionário dos marginais, de autoria de Ariel Tacla. Nele, Lacerda rememora a sucessão de dicionários do mesmo tipo publicados no Brasil desde o início do século e acrescenta o Bambambãa, de Orestes Barbosa, comentando: "continha um glossário dos malandros e gatunos hoje reunidos na denominação legalística e forencesca de marginais". Ficamos sabendo, entretanto, que foi ele, Lacerda, quem demoveu Tacla de intitular seu livro de "Linguajar das prisões", substituindo-o pelo título finalmente adotado, Dicionário dos marginais. Para justificar seu interesse pelo assunto, Lacerda encerra o prefácio com uma nota sintomática: "Este livro não é apenas curiosidade, é uma contribuição séria à evolução do idioma, que em sucessivas fases recebeu contribuições desse gênero, vindas lá de baixo, de fora da boa sociedade, a qual afinal incorpora, não raro destorcida, a gíria dos inconformados e incompossíveis”. Ver Misse (1999).
} 
gentes" ou mesmo "crimináveis", passaram a ser utilizados pelo homem comum com uma frequência inusitada se comparada a épocas anteriores, inclusive em filmes e músicas de grande alcance público.

O crescimento da representação social de um "aumento da violência" acompanhou-se também de uma generalização e banalização no emprego de códigos e linguagens antes contidos aos segmentos sociais que os criaram e que eram vistos como constituindo um mundo à parte. Se isso indica alguma coisa além da mera banalização desses códigos ou linguagens, não é improvável a hipótese de que o submundo, tal como existia antes, está desaparecendo enquanto um lugar separado, tornando-se cada vez mais poroso e menos delimitado do que antes. Isso poderia sugerir uma "ampliação" da sujeição criminal "para fora" de sua antiga demarcação espacial e social, uma "acumulação social" que estaria retirando progressivamente o sentido ao próprio processo de sujeição criminal. Essa acumulação, pelo menos quanto aos agentes de algumas práticas crimináveis, poderia estar indicando a tendência ao "desaparecimento" da sujeição criminal, isto é, à produção de uma crescente zona sombreada entre a antiga demarcação da sujeição criminal e a demarcação do universo normalizado. Ordens legítimas coabitando e emergência de zonas de "sociabilidade violenta" convivendo com a ordem legítima normalizada (Machado da Silva, 2004) não poriam fim à sujeição criminal, mas a encolheriam e a restringiriam às práticas mais "duras" do "núcleo forte".

O uso de expressões de gíria emula uma imagem social de "malandro" tanto quanto o uso do palavrão está associado às imagens do "macho" e da "virilidade". Se o uso dessas expressões generaliza-se para além de seus contextos de uso frequente, isso pode indicar que os "valores" contidos nessas imagens sociais ampliaram-se para mais segmentos sociais do que antes. Do mesmo modo, os "valores" contidos, seja 
nos significados contextuais das gírias e palavrões, seja em seu significado ambíguo-metafórico (Misse, 1979), ganharam também maior abrangência social ou, pelo menos, deixaram de ser demarcados e contidos no submundo da sujeição criminal. Não se trata apenas da substituição de expressões com um mesmo significado contextual, como usar "filho da puta" em lugar de "canalha”, mas de uma apropriação ampliada de significados novos, que relativizam ou banalizam outros significados anteriormente contidos pelo autocontrole pessoal e pela reação moral. Chamar, por exemplo, numa conversação amena, ao cadáver de alguém assassinado, de "presunto", denota uma relativização moral que ecoa significados anteriormente contidos no submundo criminal ou policial e para os quais a sociedade abrangente criava processos pouco flexíveis de demarcação moral. Pode denotar, também, para quem o fala, uma identificação com essa relativização moral, emulada como uma "superioridade" e uma indiferença blasé 34 que, anteriormente, ficava contida aos peritos do submundo (bandidos, contraventores, policiais, carcereiros, técnicos médico-legais, escrivães, jornalistas policiais etc.).

A emulação pública desse tipo de "superioridade moral" pela utilização dos códigos e imagens de malandro (no emprego abundante de gírias) ou de macho (no emprego abundante de palavrões) possui algumas afinidades com as representações de superioridade moral que participam da autoleitura que agentes de práticas criminais podem fazer de si mesmos num dos tipos de sujeição criminal. Afinidades também transmitem significados a cursos de ação que interligam a malandragem ao uso da força, via machismo, transformando o sentido tradicional da "astúcia" (próprio à idealização do malandro) em "astúcia no emprego da força" e, depois, simplesmente, em "emprego da força", principalmente quando os recursos alternativos (e não violentos) de astúcia (certas habilidades, por exemplo) ficaram escassos ou são hoje menos socializados que antes. 
O que antes participava de uma ilegitimidade sistêmica vai ganhando alguma legitimidade em certos segmentos sociais até transformar-se numa ordem legítima paralela à ordem legítima dominante, de que se faz uso quando necessário (o contexto demarcará a necessidade, a adequação de sentido e a legitimidade). A emulação pública da "superioridade moral", nesse caso, contribui para a reprodução social da sujeição criminal, principalmente em ambientes sociais onde crianças e adolescentes partilham sua socialização com grupos de referência vinculados ao submundo. Paulo Lins, em seu romance etnográfico Cidade de Deus, oferece inúmeros exemplos desse processo pelo qual significados de superioridade moral são associados à sujeição criminal através de códigos e linguagens que "passam" essa informação. A valorização do "proibido", do "clandestino", tão comum nos primeiros anos da adolescência de diferentes gerações normalizadas, facilita essa transmissão quando se associa ao consumo de drogas consideradas ilícitas. Se para a geração de classe média que nasceu nos anos 1940 ou 1950, fumar um mero cigarro - mercadoria lícita -, aos 10 anos, emulava uma "superioridade" em seus grupos juvenis de referência, por denotar "maioridade", "vida adulta" e "virilidade", para a geração que nasceu nos anos 1960, a maconha cumpriu esse papel e, nos anos 1980, também a cocaína. Como essas são mercadorias ilícitas, aprofundou-se o significado da "clandestinidade", associando não intencionalmente, no consumidor, o mundo do consumo ao mundo do tráfico. A antiga linguagem do tráfico se generaliza, ganha mais expressões e vocábulos e é, muitas vezes, partilhada "clandestinamente" por muitos dos meros consumidores. A criminalização do consumo facilitou também essa conexão de sentido, quando não produz diretamente a sujeição criminal através do encarceramento do consumidor nos espaços fechados da sujeição criminal que são os institutos para "menores", os presídios e as penitenciárias. Em condições 
sociais em que os recursos para a aquisição da droga são escassos, criam-se novos canais através dos quais o consumidor pode se transformar, também, em traficante e se submeter à sujeição criminal. De certa maneira, pode-se dizer que o processo social que constrói a sujeição criminal cria também os próprios dispositivos de sua reprodução ampliada. Além das penitenciárias e internatos de menores, um dos principais dispositivos desse processo social é a polícia, e a sua maior ou menor vulnerabilidade ao "mundo do crime" é um seguro indicador do grau de ampliação, acumulação ou extensão da sujeição criminal para além dos limites sociais de sua demarcação convencional.

\section{Michel Misse}

é professor do Programa de Pós-Graduação em Sociologia e Antropologia do Instituto de Filosofia e Ciências Sociais da UFRJ. É pesquisador do CNPq e Faperj.

\section{Referências bibliográficas}

AGAMBEM, G. 2007. Homo sacer: o poder soberano e a vida nua I. Belo Horizonte: Ed. UFMG.

ALTHUSSER, L. 1972. Aparelhos ideológicos de Estado. Rio de Janeiro: Paz e Terra.

BECKER, H. S. 1963. Outsiders: studies in the Sociology of Deviance. New York: The Free Press of Glencoe.

BUTLER, J. 1997. The psychic life of power: theories in subjection. Stanford: Stanford University Press. Press.

DAS, V. 1989. "Subaltern as perspective”. In: GUHA, R. (org.). Subaltern studies VI. New Delhi: Oxford University Press.

2005. Life and words: violence and the descent into the ordinary.

Los Angeles: University of California Press.

et al. (orgs.). 1997. Violence and subjectivity. Los Angeles: University of California Press.

ERIKSON, K. T. 1962. "Notes on the Sociology of Deviance". Social problems, vol. 9, Spring, pp. 207-314. 
FOUCAULT, M. 1977. Vigiar e punir: nascimento da prisão. Rio de Janeiro: Vozes.

. 1984. História da sexualidade II: o uso dos prazeres. Rio de Janeiro: Graal.

. 1988. História da sexualidade I: a vontade de saber. Rio de Janeiro: Graal.

2006. A hermenêutica do sujeito. São Paulo: Martins Fontes.

GOFFMAN, E. 1962. Stigma: notes on the management of spoiled identity. Englewood Cliffs (New Jersey): Prentice-Hall.

GRILLO, C. C. 2008. Fazendo o doze na pista: um estudo de caso do mercado ilegal de drogas na classe média. Dissertação de mestrado. Rio de Janeiro: UFRJ.

LEMERT, E. M. 1951. Social pathology. New York: McGRaw-Hill.

1967. Human deviance, social problems and social control. Englewood Cliffs (New Jersey): Prentice-Hall.

KITSUSE, J. 1962. "Societal reaction to deviant behavior: problems of theory and methods". Social problems, vol. 9, Winter, pp. 247-256.

LÉVI-STRAUSS, C. 1985. "O feiticeiro e sua magia”. In: Antropologia estrutural. Rio de Janeiro: Tempo Brasileiro.

MACHADO DA SILVA, L. A. 2004. "Sociabilidade violenta: por uma interpretação da criminalidade contemporânea no Brasil urbano”. In: RIBEIRO, L. C. (org.). Metrópoles: entre a cooperação e o conflito. São Paulo: Perseu Abramo.

MAGALHÃES, C. A. T. 2006. O crime segundo o criminoso: um estudo de relatos sobre a experiência da sujeição criminal. Tese de doutorado. Rio de Janeiro: UFRJ.

MELOSSI, D. 2000. "Changing representations of the criminal". In: GARLAND, D.; SPARKS, R. (orgs.). Criminology and social theory. Oxford: Oxford University Press.

MISSE, M. 1979. O estigma do passivo sexual. Rio de Janeiro: Achiamé/ Socii.

1999. Malandros, marginais e vagabundos: a acumulação social da violência no Rio de Janeiro. Tese de doutorado. Rio de Janeiro: Iuperj. . 2006. Crime e violência no Brasil contemporâneo: estudos de sociologia do crime e da violência urbana. Rio de Janeiro: Lumen Juris, 2006.

. 2007. "Notas sobre a sujeição criminal de crianças e adolescentes”. In: SÉ, J. T. S.; PAIVA, V. (orgs.). Jovens em conflito com a lei. Rio de Janeiro: Garamond.

. 2008a. "Sobre a acumulação social da violência no Rio de Janeiro”. Civitas, Porto Alegre, vol. 8, n 3, pp. 371-385. 
2008b. "Sobre a construção social do crime no Brasil". In: MISSE, M. (org.). Acusados e acusadores: estudos sobre ofensas, acusações e incriminações. Rio de Janeiro: Revan.

NERI, N. 2009. Tirando a cadeia dimenor. Dissertação de mestrado. Rio de Janeiro: UFRJ.

RAMALHO, J. R. 1983. Mundo do crime: a ordem pelo avesso. Rio de Janeiro: Graal.

TANNENBAUM, F. 1938. Crime and the community. Boston: Ginn.

TEIXEIRA, C. P. 2009. A construção social do "ex-bandido": um estudo sobre sujeição criminal e pentecostalismo. Dissertação de mestrado. Rio de Janeiro: UFRJ.

WIEWIORKA, M. 2008. Neuf leçons de sociologie. Paris: Éditions Robert Laffont.

ZALUAR, A. 2004. Integração perversa: pobreza e tráfico de drogas. Rio de Janeiro: Ed. FGV.

\section{Outros materiais}

DIÁRIO OFICIAL DO ESTADO DO RIO DE JANEIRO. Disponível em $<$ http://www.isp.rj.gov.br/Conteudo.asp?ident=150>. Acesso em $30 / 10 / 2009$. 


\section{CRIME, SUJEITO E SUJEIÇÃO CRIMINAL: ASPECTOS DE UMA CONTRIBUIÇÃO ANALÍTICA SOBRE A CATEGORIA "BANDIDO"}

MICHEL MISSE

O autor toma, neste artigo, o conceito de "sujeição criminal" (Misse, 1999), visando contribuir para uma melhor compreensão de como opera a categoria "bandido" na sociedade brasileira. Nesse sentido, recupera temas contemporâneos da chamada "teoria do sujeito" bem como das abordagens clássicas sobre ator e agência, rótulo e estigma, para melhor definir o conjunto de questões envolvidas em sua contribuição.

Palavras-chave: Criminalidade; Violência; Criminoso; Bandido; Sujeição criminal.

\section{CRIME, SUBJECT AND CRIMINAL SUBJECTION: ASPECTS OF A CONTRIBUTION TOWARDS BANDIT CATEGORY}

In this article the author recovers the concept of "criminal subjection" (Misse, 1999), to contribute to a better understanding of how operates the category of "bandido" (bandit) in Brazilian society. In this sense, the contemporary themes of the so-called "theory of the subject" are discussed as well as the classical approaches of actor and agency, label and stigma, to better define the range of issues involved in its contribution.

Keywords: Criminality; Violence; Criminal; Bandit; Criminal subjection. 